\title{
EFEKTIVITAS SERTIFIKASI DOSEN TERHADAP KOMPETENSI DOSEN DI POLTEKKES KEMENKES BENGKULU
}

\author{
Eliana, Desi Widiyanti, Ratna Dewi \\ Politeknik Kesehatan Kementerian Kesehatan Bengkulu, Jurusan Kebidanan, \\ Jalan Indragiri Nomor 03 Padang Harapan Kota Bengkulu \\ ratna_kos@yahoo.com
}

\begin{abstract}
Performance is measured based lecturer faculty workload includes the following principal activities of the learning plan, implement bembelajaran process, evaluating learning, guide and train, conduct research, perform community service and perform additional tasks. One of the government's efforts to improve the competence of lecturers, starting in 2008, no performance assessment program called Lecturer Certification lecturers. The importance of the program Lecturer Certification as a form of assessment of faculty performance is expected to improve the quality of education and provide benefits that can be perceived by students as output in the world of education. This study aims to determine differences in the competence of lecturers who have tersertifkasi and yet tersertifkasi in Poltekkes MoH Bengkulu 2014. This research was analytic cross-sectional study. The population in this study are all still in the polytechnic lecturers Bengkulu MoH both JFU and JFT are 85 people, samples were taken with total sampling technique. Data analysis was performed using univariate and bivariate independent $\mathrm{T}$ test. The results showed that the majority $(75.7 \%)$ lecturers already tersertiifikasi, most (64.9\%) lecturers are aged $\geq 45$ years and almost all $(83.8 \%)$ lecturers have been teaching $\geq 5$ years, and there was no difference the competence of lecturers are certified with certified faculty who have both pedagogical, professional, personal and social. It is expected that the relevant agencies to carry out monitoring and evaluation of the learning process both on students and lecturers.
\end{abstract}

Keywords: Certification, Performance Lecturer

\begin{abstract}
Abstrak : Kinerja dosen diukur berdasarkan beban kerja dosen mencakup kegiatan pokok yaitu merencanakan pembelajaran, melaksanakan proses bembelajaran, melakukan evaluasi pembelajaran, membimbing dan melatih, melakukan penelitian, melakukan pengabdian pada masyarakat dan melakukan tugas tambahan. Salah satu upaya pemerintah untuk meningkatkan kompetensi dosen, mulai tahun 2008, ada program penilaian kinerja dosen yang dinamakan Sertifikasi Dosen. Pentingnya adanya program Sertifikasi Dosen sebagai wujud dari penilaian kinerja dosen yang diharapkan dapat meningkatkan kualitas dunia pendidikan dan memberikan manfaat yang dapat dirasakan oleh mahasiswa sebagai output dalam dunia pendidikan. penelitian ini bertujuan untuk mengetahui perbedaan kompetensi dosen yang telah tersertifkasi dan belum yang tersertifkasi di Poltekkes Kemenkes Bengkulu tahun 2014. Penelitian ini adalah penelitian analitik dengan pendekatan studi potong lintang. Populasi dalam penelitian adalah semua Dosen tetap di lingkungan Poltekkes Kemenkes Bengkulu baik JFU maupun JFT berjumlah 85 orang, Sampel diambil dengan tehnik total sampling. Analisis data dilakukan secara univariat dan bivariat dengan uji $\mathrm{T}$ independen. Hasil penelitian menunjukkan bahwa sebagian besar $(75,7 \%)$ dosen sudah tersertiifikasi, sebagian besar $(64,9 \%)$ dosen sudah berusia $\geq$ 45 tahun dan hampir seluruh $(83,8 \%)$ dosen sudah mengajar $\geq 5$ tahun, serta tidak ada perbedaan kompetensi dosen yang tersertifikasi dengan dosen yang belum tersertifikasi baik kompetensi pedagogik, profesional, kepribadian dan sosial. Diharapkan instansi yang bersangkutan untuk melakukan monitoring dan evaluasi pelaksanaan proses belajar mengajar baik pada mahasiswa maupun dosen.
\end{abstract}

Kata Kunci : Sertifikasi, Kinerja Dosen

Proses belajar mengajar merupakan suatu proses yang mengandung serangkaian perbuatan pendidik dan peserta didik atas hubungan timbal balik yang berlangsung dalam situasi 
edukatif untuk mencapai tujuan. Pembelajaran adalah proses interaksi peserta didik dengan pendidik dan sumber belajar pada suatu lingkungan belajar (Dirjen.Dikti, 2001).

Peran, tugas dan tanggungjawab dosen sangat penting dalam mewujudkan tujuan pendidikan nasional, yaitu mencerdaskan kehidupan bangsa, meningkatkan kualitas manusia Indonesia, meliputi kualitas iman/takwa, akhlak mulia dan penguasaan ilmu pengetahuan, teknologi dan seni, serta mewujudkan masyarakat Indonesia yang maju, adil, makmur dan beradab. Untuk melaksanakan fungsi, peran dan kedudukan yang sangat strategis tersebut, diperlukan dosen yang profesional (Depdiknas, 2001). Menurut Undang-Undang Guru dan Dosen nomor 14 tahun 2005, dosen adalah pendidik profesional dari ilmuwan dengan tugas utama metransformasikan, mengembangkan dan menyebarluaskan ilmu pengetahuan, teknologi dan seni melalui pendidikan, penelitian dan pengabdian masyarakat.

Kinerja dosen diukur berdasarkan beban kerja dosen mencakup kegiatan pokok yaitu merencanakan pembelajaran, melaksanakan proses bembelajaran, melakukan evaluasi pembelajaran, membimbing dan melatih, melakukan penelitian, melakukan pengabdian pada masyarakat dan melakukan tugas tambahan. Beban kerja dosen sepadan dengan 12 satuan kredit semester (SKS) dan sebanyak banyaknya 16 satuan kredit semester (SKS) (Djohar, H, 2006).

Depdiknas (2004), menyatakan kinerja dosen adalah kemampuan untuk melaksanakan pekerjaan atau tugas yang dimiliki dosen dalam menyelesaikan suatu pekerjaannya. Kriteria kinerja pendidikan menurut Blazey, et al. (2001) dalam Trisnaningsih (2011) bertujuan untuk: (1) meningkatkan kinerja, kappabilitas, dan output pendidikan, (2) mempermudah komunikasi dan tukar menukar informasi tentang praktik pendidikan yang terbaik dengan berbagai tipe institusi pendidikan, dan (3) sebagai alat untuk memahami dan meningkatkan kinerja institusi pendidikan serta pedoman dalam perencanaan stratejik.

Kemampuan dosen mengajar merupakan dimensi paling utama untuk dilakukan monitoring. Penilaian ini dapat dilakukan oleh dosen sendiri, kepala sekolah maupun oleh peserta didik melalui persepsinya (Rohani dan Ahmadi, 1999). Faktor utama penyebab rendahnya mutu pendidikan adalah kondisi pengajar yaitu kualifikasinya tidak layak atau mengajar tidak sesuai bidang keahliannya. Tantangan yang terkait dengan mutu pendidik mencakup tantangan pribadi, kompetensional pribadi maupun ketrampilan pendidik dalam melaksanakan tugasnya (Djohar, H, 2006).

Adapun factor-faktor kinerja tersebut antara lain meliputi pengalaman, ketrampilan, usia, jenis kelamin, pendidikan, masa kerja, tanggung jawab, kepuasan kerja, persepsi, motivasi, kepemimpinan, imbalan, supervisi, kondisi kerja (Mahmudi, 2005). Hasil penelitian Mundarti (2007) menunjukkan bahwa banyak faktor yang mempengaruhi kinerja dosen dalam melaksanakan proses belajar mengajar, yaitu usia, pendidikan, persepsi dan motivasi.

Salah satu upaya pemerintah untuk meningkatkan kompetensi dosen, mulai tahun 2008, ada program penilaian kinerja dosen yang dinamakan Sertifikasi Dosen. Sertifikasi Dosen adalah proses pemberian sertifikat pendidik kepada dosen yang bertujuan untuk menilai profesionalisme dosen guna menentukan kelayakan dosen dalam melaksanakan tugas, melindungi profesi dosen sebagai agen pembelajaran di perguruan tinggi, meningkatkan proses dan hasil pendidikan, serta mempercepat terwujudnya tujuan pendidikan nasional (Dikti, 2013).

Penilaian untuk memperoleh sertifikasi Dosen terdapat ada empat (4) kompetensi yang wajib dinilai dari seorang dosen yaitu kompetensi pedagogik, profesional, sosial dan kepribadian. Kompetensi tenaga pendidik, khususnya dosen, diartikan sebagai seperangkat pengetahuan, keterampilan dan perilaku yang harus dimiliki, dihayati, dikuasai dan diwujudkan oleh dosen dalam melaksanakan tugas profesionalnya (Dikti, 2013).

Pelaksanaan program Sertifikasi Dosen ini diharapkan dapat membawa dampak positif bagi peningkatan kualitas pendidikan di Perguruan Tinggi khususnya bagi mahasiswa. Salah satu dampak positif dari adanya program, Sertifikasi Dosen yaitu adanya 
umpan balik antara dosen dan mahasiswa. Umpan balik yang dimaksud di sini seperti dengan kegiatan belajar mengajar yang terarah karena dosen yang telah tersertifikasi dapat menguasai kurikulum program studi berbasis kompetensi sehingga mahasiswa mendapatkan pengetahuan yang selalu up to date sehubungan dengan dunia era globalisasi ini. Program Sertifikasi Dosen pun akhirnya diharapkan dapat meningkatkan kualitas output bidang pendidikan di Perguruan Tinggi yang tidak lain adalah mahasiswa. Pentingnya adanya program Sertifikasi Dosen sebagai wujud dari penilaian kinerja dosen yang diharapkan dapat meningkatkan kualitas dunia pendidikan dan memberikan manfaat yang dapat dirasakan oleh mahasiswa sebagai output dalam dunia pendidikan ((Muslich, 2007).

Poltekkes Kemenkes Bengkulu mememiliki dosen sebanyak 85 orang dan yang telah tersertifikasi sebanyak 51 orang dimulai rentang tahun 2010-2013, Berdasarkan survey awal bahwa masih ada dosen yang belum memenuhi empat standar kompetensi, yaitu; kompetensi pedagogik, professional, sosial dan keperibadian. Maka dari itu penelitian ini bertujuan untuk mengetahui perbedaan kompetensi dosen yang telah tersertifkasi dan belum yang tersertifkasi di Poltekkes Kemenkes Bengkulu tahun 2014.

\section{BAHAN DAN CARA KERJA}

Penelitian ini adalah penelitian analitik dengan pendekatan studi potong lintang. Populasi dalam penelitian adalah semua Dosen tetap di lingkungan Poltekkes Kemenkes Bengkulu baik JFU maupun JFT berjumlah 85 orang, Sampel diambil dengan tehnik total sampling. Instrumen penelitian berupa kuesioner yang berisikan kompetensi dosen yang terdiri dari kompetensi pedagogik, professional, social dan keperibadian. Kuesioner ini merupakan format penilaian yang telah disahkan dan digunakan oleh Dikti penilaian kompetensi dosen pada waktu seleksi sertifikasi dosen.

Pengumpulan data dilakukan dengan cara observasi langsung terhadap dosen dimulai dari persiapan, pelaksanaan penga- jaran dan keperibadian sehari-hari serta hubungan sosial dengan lingkungan kampus. Setiap dosen diobservasi oleh 10 mahasiswa, sehingga skor yang digunakan adalah skor rata-rata dari kesepuluh mahasiswa tersebut. Analisis data dilakukan secara univariat dan bivariat dengan uji $\mathrm{T}$ independen dengan $\mathrm{CI}$ $95 \%$ dan $\alpha=0,05$.

\section{HASIL}

\section{Analisis Univariat}

\begin{tabular}{|c|c|c|}
\hline Variabel & $\begin{array}{c}\text { Frekuensi } \\
(n=74)\end{array}$ & $\begin{array}{c}\text { Presentase } \\
(100 \%)\end{array}$ \\
\hline \multicolumn{3}{|l|}{ Sertifikasi Dosen } \\
\hline $\mathrm{Ya}$ & 56 & 75,7 \\
\hline Tidak & 18 & 24,3 \\
\hline \multicolumn{3}{|l|}{ Umur } \\
\hline$\leq 45$ Tahun & 48 & 64,9 \\
\hline$>45$ Tahun & 26 & 35,1 \\
\hline \multicolumn{3}{|l|}{ Lama Mengajar } \\
\hline$\geq 5$ tahun & 62 & 83,8 \\
\hline$<5$ tahun & 12 & 16,2 \\
\hline
\end{tabular}

Hasil analisis pada tabel 1 menunjukkan bahwa sebagian besar $(75,7 \%)$ dosen sudah tersertiifikasi, sebagian besar $(64,9 \%)$ dosen sudah berusia $\geq 45$ tahun dan hampir seluruh $(83,8 \%)$ dosen sudah mengajar $\geq 5$ tahun.

Tabel 2 Gambaran Nilai Rata-Rata Kompetensi Dosen

\begin{tabular}{lccccc}
\hline \multicolumn{1}{c}{ Variabel } & N & Mean & SD & Min & Max \\
& & & & & \\
\hline Kompetensi Pedagogik & & & & & \\
Sertifikasi & 56 & 5,93 & 0,892 & 4 & 7 \\
$\begin{array}{l}\text { Belum Sertifikasi } \\
\text { Kompetensi Profesional }\end{array}$ & 18 & 5,83 & 1,043 & 3 & 7 \\
$\begin{array}{l}\text { Sertifikasi } \\
\text { Belum Sertifikasi }\end{array}$ & 56 & 5,93 & 0,912 & 4 & 7 \\
Kompetensi Kepribadian & 18 & 5,78 & 0,808 & 4 & 7 \\
$\begin{array}{l}\text { Sertifikasi } \\
\text { Belum Sertifikasi }\end{array}$ & 56 & 6,04 & 0,873 & 4 & 7 \\
Kompetensi Sosial & 18 & 5,78 & 1,166 & 2 & 7 \\
$\begin{array}{l}\text { Sertifikasi } \\
\text { Belum Sertifikasi }\end{array}$ & 56 & 5,98 & 0,884 & 4 & 7 \\
Kompetensi & 18 & 5,78 & 1,003 & 3 & 7 \\
$\begin{array}{l}\text { Umum } \\
\text { Sertifikasi Secara }\end{array}$ & & & & & \\
Belum Sertifikasi & 56 & 6,00 & 0,894 & 4 & 7 \\
\hline
\end{tabular}

Berdasarkan tabel 2 diatas dapat dilihat bahwa rata-rata nilai kompetensi pedagogik pada dosen tersertifikasi adalah 5,93 dengan standar deviasi 0,892, sedangkan untuk dosen yang belum tersertifikasi rata-rata kom- 
petensi pedagogiknya adalah 5,83 dengan standar deviasi 1,043.

Rata-rata nilai kompetensi profesional pada dosen tersertifikasi adalah 5,93 dengan standar deviasi 0,912, sedangkan untuk dosen yang belum tersertifikasi rata-rata kompetensi profesionalnya adalah 5,78 dengan standar deviasi 0,808 .

Rata-rata nilai kompetensi kepribadian pada dosen tersertifikasi adalah 6,04 dengan standar deviasi 0,873 , sedangkan untuk dosen yang belum tersertifikasi rata-rata kompetensi kepribadiannya adalah 5,78 dengan standar deviasi 1,166 .

Rata-rata nilai kompetensi sosial pada dosen tersertifikasi adalah 5,98 dengan standar deviasi 0,884, sedangkan untuk dosen yang belum tersertifikasi rata-rata kompetensi sosialnya adalah 5,78 dengan standar deviasi 1,003.

Rata-rata nilai kompetensi secara umum pada dosen tersertifikasi adalah 6,00 dengan standar deviasi 0,894, sedangkan untuk dosen yang belum tersertifikasi ratarata kompetensi secara umum adalah 5,72 dengan standar deviasi 1,018.

\section{Analisis Bivariat}

Sebelum dilakukan analisis bivariat terlebih dahulu data diuji normalitas menggunakan uji one sample kolmogorov-smirnov didapat $\rho<0,05$ berarti data tidak berdistribusi normal. Maka analisis bivariat menggunakan uji Mann Whitney dan tingkat kemaknaan $\alpha=0,05$.

Hasil uji statistik pada tabel 3 menunjukkan bahwa tidak ada perbedaan kompetensi pedagogik pada dosen tersertifikasi dengan dosen yang belum sertifikasi (nilai $\mathrm{p}=0,884$ ). Tidak ada perbedaan kompetensi profesional pada dosen tersertifikasi dengan dosen yang belum sertifikasi (nilai $\mathrm{p}=0,550$ ). Tidak ada perbedaan kompetensi kepribadian pada dosen tersertifikasi dengan dosen yang belum sertifikasi (nilai $\mathrm{p}=0,505$ ). tidak ada perbedaan kompetensi sosial pada dosen tersertifikasi dengan dosen yang belum sertifikasi (nilai $\mathrm{p}=0,524$ ). Serta tidak ada perbedaan kompetensi secara umum pada dosen tersertifikasi dengan dosen yang belum sertifikasi (nilai $\mathrm{p}=0,346$ ).

Tabel 3 Perbedaan Kompetensi Dosen yang telah Sertifikasi dengan Dosen yang Belum Sertifikasi

\begin{tabular}{|c|c|c|c|c|}
\hline Variabel & $\mathbf{N}$ & $\begin{array}{l}\text { Mean } \\
\text { Rank }\end{array}$ & $\begin{array}{l}\text { Sum of } \\
\text { Ranks }\end{array}$ & $P$ \\
\hline \multicolumn{5}{|c|}{ Kompetensi Pedagogik } \\
\hline Sertifikasi & 56 & 37,70 & 2111 & 0,884 \\
\hline Belum Sertifikasi & 18 & 36,89 & 664 & \\
\hline \multicolumn{5}{|c|}{ Kompetensi Profesional } \\
\hline Sertifikasi & 56 & 38,30 & 2145 & 0,550 \\
\hline Belum Sertifikasi & 18 & 35,00 & 630 & \\
\hline \multicolumn{5}{|c|}{ Kompetensi Kepribadian } \\
\hline Sertifikasi & 56 & 38,39 & 2150 & 0,505 \\
\hline Belum Sertifikasi & 18 & 34,72 & 625 & \\
\hline \multicolumn{5}{|l|}{ Kompetensi Sosial } \\
\hline Sertifikasi & 56 & 38,36 & 2148 & 0,524 \\
\hline Belum Sertifikasi & 18 & 34,83 & 627 & \\
\hline \multicolumn{5}{|c|}{ Kompetensi Secara Umum } \\
\hline Sertifikasi & 56 & 38,77 & 2171 & 0,346 \\
\hline Belum Sertifikasi & 18 & 33,56 & 604 & \\
\hline
\end{tabular}

Hasil uji statistik pada tabel 4 menunjukkan bahwa tidak ada perbedaan kompetensi pedagogik pada dosen yang berusia $\leq 45$ Tahun dengan dosen yang berusia $>45$ tahun (nilai $\mathrm{p}=0,257$ ). Tidak ada perbedaan kompetensi profesional pada dosen yang berusia $\leq 45$ Tahun dengan dosen yang berusia $>45$ tahun (nilai $\mathrm{p}=0,133$ ). Tidak ada perbedaan kompetensi kepribadian pada dosen yang berusia $\leq 45$ Tahun dengan dosen yang berusia $>45$ tahun (nilai $\mathrm{p}=0,340$ ). Tidak ada perbedaan kompetensi sosial pada dosen yang berusia $\leq 45$ Tahun dengan dosen yang berusia $>45$ tahun (nilai $\mathrm{p}=0,282$ ). Tidak ada perbedaan kompetensi secara umum pada dosen yang berusia $\leq 45$ Tahun dengan dosen yang berusia $>45$ tahun (nilai $\mathrm{p}=0,291$ ).

Hasil uji statistik pada tabel 5 menunjukkan bahwa tidak ada perbedaan kompetensi pedagogik pada dosen yang lama mengajar $\geq 5$ Tahun dengan dosen yang berusia $<5$ tahun (nilai $\mathrm{p}=0,308$ ). Tidak ada perbedaan kompetensi profesional pada dosen yang lama mengajar $\geq 5$ Tahun dengan dosen yang berusia $<5$ tahun (nilai $p=0,240$ ). Tidak ada perbedaan kompetensi kepribadian pada dosen yang lama mengajar $\geq 5$ Tahun dengan dosen yang berusia $<5$ tahun (nilai $\mathrm{p}=0,555$ ). Tidak ada perbedaan kompetensi sosial pada dosen yang lama 
mengajar $\geq 5$ Tahun dengan dosen yang berusia $<5$ tahun (nilai $\mathrm{p}=0,889$ ). Tidak ada perbedaan kompetensi secara umum pada dosen yang lama mengajar $\geq 5$ Tahun dengan dosen yang berusia $<5$ tahun (nilai $p=0,889$ ).

Tabel 4 Perbedaan Kompetensi Dosen Dilihat dari Umur

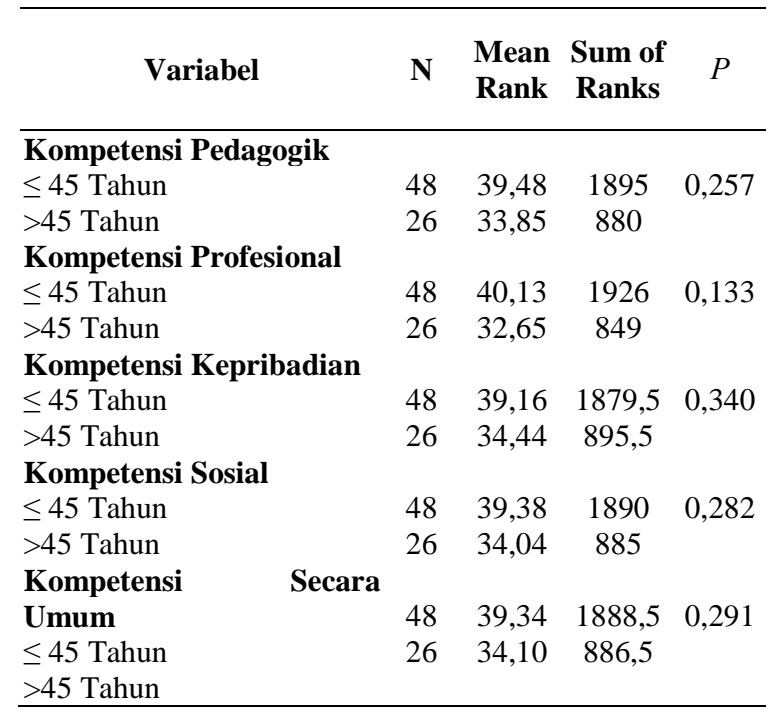

Tabel 5 Perbedaan Kompetensi Dosen Dilihat dari Lama Mengajar

\begin{tabular}{lcccc}
\hline \multicolumn{1}{c}{ Variabel } & N & $\begin{array}{c}\text { Mean } \\
\text { Rank }\end{array}$ & $\begin{array}{c}\text { Sum of } \\
\text { Ranks }\end{array}$ & $P$ \\
\hline $\begin{array}{l}\text { Kompetensi Pedagogik } \\
\geq 5 \text { tahun }\end{array}$ & 62 & 36,44 & 2259 & 0,308 \\
$\begin{array}{l}<5 \text { tahun } \\
\text { Kompetensi Profesional }\end{array}$ & 12 & 43,00 & 516 & \\
$\begin{array}{l}\geq 5 \text { tahun } \\
<5 \text { tahun }\end{array}$ & 62 & 36,27 & 2249 & 0,240 \\
$\begin{array}{l}\text { Kompetensi } \\
\text { Kepribadian }\end{array}$ & 12 & 43,83 & 526 & \\
$\begin{array}{l}\geq 5 \text { tahun } \\
<5 \text { tahun }\end{array}$ & 62 & 36,89 & 2287 & 0,555 \\
$\begin{array}{l}\text { Kompetensi Sosial } \\
\geq 5 \text { tahun }\end{array}$ & 12 & 40,67 & 488 & \\
$\begin{array}{l}<5 \text { tahun } \\
\text { Kompetensi } \quad \text { Secara }\end{array}$ & & & & \\
$\begin{array}{l}\text { Umum } \\
\geq 5 \text { tahun }\end{array}$ & 62 & 37,35 & 2316 & 0,889 \\
\hline 5 tahun & 12 & 38,25 & 459 & \\
\hline
\end{tabular}

\section{PEMBAHASAN}

Hasil penelitian menunjukkan bahwa sebagian besar $(75,7 \%)$ dosen di Poltekkes Kemenkes Bengkulu sudah tersertiifikasi. Keadaan ini menunjukan sebagai bukti bahwa dosen yang ada dilingkungan Poltekkes Kemenkes Bengkulu telah diaku sebagi tenaga profesional. Menurut UU nomor 14 tahun 2005, Sertifikat pendidik adalah bukti formal sebagai pengakuan yang diberikan kepada guru dan dosen sebagai tenaga profesional. Sertifikasi dosen merupakan program pemberian tunjangan profesi kepada dosen agar dapat meningkatkan kreatifitas dan kualitas kinerja sehingga mampu mengatualisasikan potensi diri secara optimal sebagai tercermin dalam misi tridharma perguruan tinggi (pengajaran, penelitian dan pengabdian kepada masyarakat.

Kriteria kinerja pendidikan menurut Blazey, et al. (2001) dalam Trisnaningsih (2011) bertujuan untuk: (1) meningkatkan kinerja, kapabilitas, dan output pendidikan, (2) mempermudah komunikasi dan tukar menukar informasi tentang praktik pendidikan yang terbaik dengan berbagai tipe institusi pendidikan, dan (3) sebagai alat untuk memahami dan meningkatkan kinerja institusi pendidikan serta pedoman dalam perencanaan stratejik.

Hasil penelitian menunjukkan bahwa tidak ada perbedaan kompetnsi dosen yang tersertifikasi dengan dosen yang belum tersertifikasi baik kompetensi pedagogik, profesional, kepribadian dan sosial. Hasil ini sejalan dengan hasil penelitian Raudhoh \& Muhammad (2012) yang menyatakan bahwa kinerja dosen pada kelompok dosen beretos kerja tinggi yang sudah lulus sertifikasi sama dengan Kinerja kelompok dosen yang belum sertifikasi. Dengan demikian dapat disimpulkan bahwa Kebijakan Pendidikan yang berupa sertifikasi dosen di IAIN STS Jambi belum efektif untuk dijadikan sarana meningkatkan kinerja dosen.

Becker et al. (2001) mengatakan bahwa kompetensi mengacu pada karakter knowledge, skill, dan abilities setiap indivi$\mathrm{du}$ atau karakter personal yang mempengaruhi job performance individu secara langsung. Pada sistem pengajaran, kompetensi digunakan untuk mendeskripsikan kemampuan profesional yaitu kemampuan untuk menunjukkan pengetahuan dan konseptualisasi pada tingkat yang lebih tinggi. Kompetensi ini dapat diperoleh melalui pendidikan, pelatihan dan penga- 
laman lain sesuai tingkat kompetensinya (Mulyasa, 2004).

Menurut undang-undang No 14 tahun 2005 pasal 69 ayat 2, kompetensi dosen meliputi kompetensi pedagogik, kompetensi kepribadian, kompetensi sosial, dan kompetensi profesional. Kompetensi pedagogik adalah kemampuan mengelola pembelajaran peserta didik. Kompetensi ini dapat dilihat dari kemampuan merencanakan program belajar mengajar, kemampuan melaksanakan interaksi atau mengelola proses belajar mengajar, dan kemampuan melakukan penilaian. Kompetensi kepribadian merupakan kemampuan personal yang mencerminkan kepribadian yang mantap, stabil, dewasa, arif, dan berwibawa serta dapat menjadi teladan bagi peserta didik, dan berakhlak mulia. Surya (2003) menyebut kompetensi kepribadian ini sebagai kompetensi personal, yaitu kemampuan pribadi seorang dosen yang diperlukan agar dapat menjadi dosen yang baik.

Surya (2003) mengemukakan kompetensi sosial adalah kemampuan yang diperlukan oleh seseorang agar berhasil dalam berhubungan dengan orang lain. Dalam kompetensi sosial ini termasuk keterampilan dalam interaksi sosial dan melaksanakan tanggung jawab sosial. Kompetensi profesional merupakan penguasaan materi pembelajaran secara luas dan mendalam yang mencakup penguasaan materi kurikulum mata pelajaran di sekolah dan subtansi keilmuan yang menaungi materi serta penguasaan terhadap struktur dan metodologi.

Hasil penelitian Mundarti (2007) menunjukkan bahwa banyak faktor yang mempengaruhi kinerja dosen dalam melaksanakan proses belajar mengajar, yaitu usia, pendidikan, persepsi dan motivasi.

Hasil penelitian menunjukkan bahwa tidak ada perbedaan kompetnsi dosen yang berusia $\geq 45$ tahun dengan dosen yang berusia $<45$ tahun baik kompetensi pedagogik, profesional, kepribadian dan sosial. Keadaan ini disebabkan oleh sebagian besar $(64,9 \%)$ dosen sudah berusia $\geq 45$ tahun yang berarti bahwa dosen di lingkungan Poltekkes Ke- menkes Bengkulu sebagian besar telah senior.

Hasil penelitian ini tidak sejalan dengan penelitian Mundarti (2007) yang menyatakan bahwa usia mempengaruhi kinerja dosen dalam melaksanakan proses belajar mengajar. Hasil ini juga tidak sejalan dengan pendapat Mulyasa (2004) yang menyatakan bahwa pada sistem pengajaran, kompetensi digunakan untuk mendeskripsikan kemampuan profesional yaitu kemampuan untuk menunjukkan pengetahuan dan konseptualisasi pada tingkat yang lebih tinggi. Kompetensi ini dapat diperoleh melalui pendidikan, pelatihan dan pengalaman lain sesuai tingkat kompetensinya. Dimana, pengalaman akan semakin tinggi dengan usia yang semakin tua.

Hasil penelitian menunjukkan bahwa tidak ada perbedaan kompetnsi dosen lama mengajar $\geq 5$ tahun dengan dosen yang lama mengajar $<5$ tahun baik kompetensi pedagogik, profesional, kepribadian dan sosial. Hal ini didukung dengan ditemukannya hampir seluruh $(83,8 \%)$ dosen di Poltekkes Kemenkes Bengkulu sudah mengajar $\geq 5$ tahun. Hasil penelitian ini sejalan dengan penelitian Mundarti (2011) bahwa tidak ada hubungan masa kerja dengan kinerja dosen dalam melaksanakan proses belajar mengajar di Program Studi Kebidanan Magelang.

Hasil ini tidak sejalan dengan hasil penelitian Yuliyani (2010) yang menunjukkan bahwa terdapat hubungan yang signifikan antara pengalaman mengajar dengan kompetensi profesional pada guru PKn di SMP Negeri Kabupaten Karanganyar. Kompetensi guru dapat dinilai penting sebagai alat seleksi dalam penerimaan calon guru, juga dapat dijadikan sebagai pedoman dalam rangka pembinaan dan pengembangan tenaga guru.

\section{KESIMPULAN}

Berdasarkan hasil yang diperoleh peneliti dapat disimpulkan bahwa sebagian besar dosen sudah tersertiifikasi, dan tidak ada perbedaan kompetensi dosen yang tersertifikasi dengan dosen yang belum terser- 
tifikasi baik kompetensi pedagogik, profesional, kepribadian dan sosial.

Diharapkan instansi yang bersangkutan untuk melakukan monitoring dan evaluasi pelaksanaan proses belajar mengajar baik pada mahasiswa maupun dosen, serta

\section{DAFTAR RUJUKAN}

Depdiknas. 2001. Pendidikan Sebagai Sistem. Dirjen Dikti. Jakarta.

Direktorat Jenderal Pendidikan Tinggi Kementerian Pendidikan Nasional. 2013. Buku Pedoman Sertifikasi Pendidik untuk Dosen (Serdos) Terintegrasi, Buku 1 Naskah Akademik. .2013. Buku Pedoman Sertifikasi Pendidik untuk Dosen (Serdos) Terintegrasi, Buku 1 Penilaian Portofolio. Jakarta

2007. Peraturan Pemerintah No. 47 Tahun 2007 tentang Sertifikasi Dosen. Jakarta . 2011. Kajian Analisis Sistem Sertifikasi Dosen. Jakarta.

Djohar, H. 2006. Pendidikan Dan Pembinaannya. CV.Gravika Indah, Yoyakarta.

Kementerian Pendidikan Nasional. 2005. UndangUndang Nomor 14 Tahun 2005 tentang Guru dan Dosen

Mahmudi. 2005. Manajemen Kinerja Sektor Publik,.Akademi Manajemen Perusahaan YKPN. Yogyakarta. perlunya melakukan uji kompetensi secara berkala kepada semua dosen baik yang telah tersertifikasi maupun yang belum tersertifikasi sebagai upaya meningkatkan kinerja dosen yang ada.

Muslich. 2007. Sertifikasi Guru Мепији Profesionalisme Pendidik. Jakarta: Bumi Aksara

Mulyasa, E. 2005. Menjadi Guru Profesional Menciptakan Pembelajaran Kreatif Dan Menyenangkan. PT. Remaja Rosdakarya., Bandung.

Mundarti. 2007. Faktor-Faktor Yang Mempengaruhi Kinerja Dosen Dalam Melaksanakan Proses Belajar Mengajar Di Prodi Kebidanan Magelang Politeknik Kesehatan Semarang Tahun Akademik 2005 / 2006.

Rohani dan Ahmadi. 1999. Pengelolaan Pengajara.

Rineka Cipta, Jakarta.

Trisnaningsih. 2011. Faktor-Faktor Yang Mempengaruhi Kinerja Dosen Akuntansi. Jurnal Akuntansi \& Auditing Volume 8/No. 1/November 2011: 1-94

Yuliani. 2010. Hubungan Antara Pengalaman Mengajar Dan Motivasi Mengajar Dengan Kompetensi Guru Pendidikan Pancasila Dan Kewarganegaraan Di Sekolah Menengah Pertama Di Kabupaten Karanganyar. 